\title{
Fe speciation and cycling in marine methanogenic sediments
}

C.C. MCKINLEY ${ }^{1}$, E.A. SOLOMON ${ }^{1}$, R.M. BUNDY ${ }^{1}$, T.L. WHORLEY $^{1}$ AND C.L. HOFFMAN ${ }^{1,2}$

${ }^{1}$ University of Washington, School of Oceanography, 1503 NE Boat St, Seattle, WA 98195; cmck2@uw.edu, esolomn@uw.edu,rbundy@uw.edu,twhorley@uw.edu

${ }^{2}$ Joint Institute for the Study of Atmosphere and Ocean, 3737 Brooklyn Ave NE, Seattle, clhoffma@uw.edu

Microbes living in marine sediment pore water use electron acceptors in order of decreasing chemical potential for dissimilatory respiration: $\mathrm{O}_{2}$ is consumed first, followed by $\mathrm{NO}_{3}, \mathrm{Fe}$ and $\mathrm{Mn}$, and finally $\mathrm{SO}_{4}$ before the reduction of $\mathrm{CO}_{2}$ to form methane. In recently collected samples from IODP Site U1519, offshore New Zealand, high concentrations of Fe were measured below the sulfate-methane transition zone (SMTZ) indicating that the anaerobic respiration "order" is oversimplified. At this location, Fe concentrations are relatively low $(1.58-53.25 \mu \mathrm{M})$ until 24 meters below seafloor (mbsf), approximately $10 \mathrm{~m}$ below the SMTZ. Fe concentrations increase below 24 mbsf, with an average concentration of $115.3 \mu \mathrm{M}$. The release of $\mathrm{Fe}$ to the pore water below the SMTZ can be the result of Fe-reduction through $\mathrm{Fe}$-mediated Anaerobic Oxidation of Methane (Fe-AOM) or Dissimilatory Iron Reduction (DIR). We present preliminary pore water geochemistry including new Fe speciation data from Site U1519 and from cores collected along the Hikurangi margin during the 2019 SAFFRONZ cruise to investigate this phenomenon. This suite of data is designed to: 1) resolve whether $\mathrm{Fe}$ release below the SMTZ is the result Fe-AOM or driven by DIR, 2) to determine the amount of Fe that is sequestered in authigenic carbonate and sulfide minerals, and 3) whether these processes drive a diffusive flux of Fe to bottom water due to organic complexation. The deep reduction of Fe may have important implications for our understanding of the global $\mathrm{CH}_{4}$ cycle and the $\mathrm{Fe}$ budget of the ocean. 